\title{
Effect of Drug-Induced Sedation Endoscopy on the Decision of Treatment Plan in Patients with Obstructive Sleep Apnea
}

\author{
Sung Min Lee, Sung Hee Bae, Kang-Hyun Lee, Ho Jun Lee, \\ Hae Sang Park, Jun Ho Lee, Chan Hum Park, and Dong-Kyu Kim \\ Department of Otorhinolaryngology-Head and Neck Surgery, Chuncheon Sacred Heart Hospital, \\ Hallym University College of Medicine, Chuncheon, Korea
}

\author{
약물유도 수면내시경검사가 폐쇄성 수면무호흡증 환자의 치료 방침 결정에 미치는 영향 \\ 이성민 · 배승희 · 이강현 · 이호준 · 박혜상 - 이준호 - 박찬흠 · 김동규 \\ 한림대학교 의과대학 춘천성심병원 이비인후-두경부외과학교실
}

\author{
Received August 23, 2017 \\ Revised November 6,2017 \\ Accepted November 7, 2017 \\ Address for correspondence \\ Dong-Kyu Kim, MD, PhD \\ Department of Otorhinolaryngology- \\ Head and Neck Surgery, \\ Chuncheon Sacred Heart Hospital, \\ Hallym University \\ College of Medicine, 77 Sakju-ro, \\ Chuncheon 24253, Korea \\ Tel $+82-33-240-5180$ \\ Fax $+82-33-241-2909$ \\ E-mail doctordk@naver.com
}

\begin{abstract}
Background and Objectives Drug-induced sedation endoscopy (DISE) has recently gained popularity among otolaryngologists because it can provide direct information of upper airway obstruction in patients with obstructive sleep apnea (OSA). In that regard, we examined how DISE examination affected the decision of clinician's treatment plan and the consequent patient's compliance in OSA patients.

Subjects and Method All enrolled patients were classified into two groups according to the method of upper airway evaluation employed: a physical examination only group and a physical examination combined with DISE group. The clinician's treatment plan was categorized into the following four groups: sleep surgery, positive airway pressure, oral appliance, and sleep surgery combined with oral appliance. The change of patient's compliance was also evaluated.

Results There were several differences in how DISE evaluation affected the decision of clinician's treatment plan and patient's compliance between the two groups. The rate for sleep surgery fell from $69.6 \%$ to $15.9 \%$; on the other hand, the rate for positive airway pressure, oral appliance and sleep surgery combined with oral appliance all increased from $13.0 \%$ to $36.2 \%$, $14.5 \%$ to $26.6 \%$, and $2.9 \%$ to $21.3 \%$, respectively. The patient's compliance also changed after DISE evaluation: sleep surgery, positive airway pressure, oral appliance and sleep surgery combined with oral appliance all increased from $78.1 \%$ to $87.9 \%, 16.7 \%$ to $76.0 \%, 25.0 \%$ to $87.3 \%$, and $50.0 \%$ to $91.03 \%$, respectively.

Conclusion We found that DISE examination influences the decision of clinician's treatment plan and patient's compliance. We suggest additional cohort studies to confirm these findings. Korean J Otorhinolaryngol-Head Neck Surg 2018;61(6):295-9
\end{abstract}

Key Words Endoscopy · Obstructive sleep apnea · Oral appliance · Positive airway pressure $\cdot$ Surgery.

\section{서 론 \\ 수면 중 상기도의 폐쇄로 인해 저호흡 및 무호흡 등 환기장 애를 유발시키는 수면 호흡장애로서, 주기적으로 혈중 산소 폐쇄성 수면무호흡증(obstructive sleep apnea, OSA)은 포화도의 감소를 유발시켜 주간 졸림증, 조간 두통 등과 같}

This is an Open Access article distributed under the terms of the Creative Commons Attribution Non-Commercial License (http://creativecommons.org/licenses/by-nc/4.0) which permits unrestricted non-commercial use, distribution, and reproduction in any medium, provided the original work is properly cited. 
은 다양한 임상 양상을 보이는 질환이다.1) 폐쇄성 수면무호 흡증 환자에서 나타나는 상기도 폐쇄 부위는 비강에서부터 구인두, 편도, 설근부, 하인두 및 후두에 이르기까지 다양하 며, 상기도의 모든 부분에서 발생 가능하다. 그러므로 폐쇄 부위를 정확히 확인하는 것은 폐쇄성 수면무호흡증 환자 치 료에 있어서 가장 중요한 과정이라 할 수 있다. ${ }^{2)}$ 치료방법으 로는 수술적인 방법과, 양압기 치료(positive airway pressure treatment), 구강 내 장치(oral appliance) 등의 비수술적인 방 법이 있는데, 수술적 치료는 출혈과 통증, 수술 후 반흔에 의 한 불편감, 완치의 어려움 및 증상 재발 등의 단점을 지니고 있다.,2) 또한, 양압기 치료는 장비가 비싸고 이동성이 제한되 며 소음과 마스크 착용 시의 불편함으로 인한 낮은 순응도 의 문제점을 지니고, 구강 내 장치는 저작시 불편감, 턱 관절 부위 통증 등의 한계점을 지닌다., ${ }^{3,4}$

폐쇄성 수면무호흡증 환자의 상기도 폐쇄 부위를 진단하 는 방법은 매우 다양한데, 구강과 비강에 대한 단순한 내시경 적 관찰에서부터 굴곡내시경을 이용해 역발살바법(reverse Valsalva) 시에 상기도 폐쇄 부위를 관찰하는 Mueller maneuver, 상기도의 측면을 단순 촬영하여 두개골 계측 인자를 평가하는 두부방사선 계측분석(cephalometry analysis), 상기 도의 압력을 측정하여 폐쇄 부위를 결정하는 상기도 압력측 정검사(manometry), 약물유도 수면 중 굴곡내시경을 이용해 폐쇄 부위를 관찰하는 약물유도 수면내시경(drug-induced sedation endoscopy, DISE) 등이 있다. 다양한 폐쇄 부위 검 사 방법 중 약물유도 수면내시경은 기존의 상기도 폐쇄 부위 검사가 각성 상태에 시행되는 검사라는 한계점을 극복하기 위해 도입된 검사방법으로, 각성 상태가 아닌 약물유도 수면 상태에서 굴곡 비인두내시경을 이용하여 상기도(비강, 비인 두, 연구개부, 설근부, 하인두, 후두)의 역동적인 변화를 관찰 하는 방법이다. ${ }^{5)}$ 그리고 확인된 폐쇄 부위에 따라 적절한 치 료 방법을 선택할 수 있어 수술의 효과를 높임과 동시에 불 필요한 수술을 줄일 수 있을 것이라 예상된다. ${ }^{6-8)}$ 그러므로 저자들은 본 연구에서 약물유도 수면내시경검사를 시행하기 전후를 비교하여 의사들의 치료방법 선택이 어떻게 변화하 였고 환자들의 치료 순응도가 어떻게 달라졌는지 결과를 분 석하고자 하였다.

\section{대상 및 방법}

\section{대상 환자}

2009년 1월부터 2016년 12월까지 코골이, 무호흡 혹은 주간 졸림증으로 이비인후과를 방문하여 수면 검사를 시행 받은 환자를 대상으로 후향적 연구를 시행하였다. 이 연구는 본 대
학병원의 IRB 심의를 받아 진행하였다(No. 2016-23). 환자들 은 수면 검사에서 무호흡-저호흡 지수(apnea-hypopnea index, $\mathrm{AHI}$ 가 5 이상이면서 무호흡증과 관련된 주간 증상이 있으 면 폐쇄성 수면무호흡증으로 진단하였다. 중증도(severity)는 $\mathrm{AHI}$ 가 5 이상 15 미만일 경우 경증(mild), 15 이상 30 미만일 경우 중등도(moderate), 30 이상인 경우를 중증(severe)으로 분류하였다. 저자들은 2013년 3월부터 폐쇄성 수면무호흡증 으로 진단된 환자에서 약물 알러지 등 약제 사용의 금기에 해 당되거나 환자가 임의로 거부하지 않는 한 모든 이에게 약물 유도 수면내시경검사를 시행하였다.

본 연구에서의 제외기준으로는 폐쇄성 수면무호흡증으로 진단된 환자 중 1) 신체 검진에서 Friedman stage I에 해당되 어 수술적 치료가 최우선으로 고려되는 경우, 2) 구개수구개인 두성형술(uvulopalatopharyngoplasty) 혹은 변형된 구개성 형술의 한 종류를 이미 시행 받은 경우, 3) 구강 내 장치를 고 정할 치아가 충분히 있지 않거나 치아 교정 및 임플란트 시술 등 향후 교합의 변화가 예상되는 경우, 4) 기존에 양압기를 사 용하여 적응하지 못한 경우나 양압기 사용에 제한적인 요소 가 있는 경우, 5) 2013년 3월 이후 약물유도 수면내시경검사를 시행 받지 않은 환자이다. 본 연구에서 환자들의 순응도는 의료진이 제시한 치료 방침(수술적 혹은 비수술적)을 환자가 받아들이고 이를 실제로 적용한 경우로 정의하였으며, 특히 양압기 및 구강 내 장치는 하루 4시간 이상, 1 주일에 4일 이상 6 개월간 지속적으로 사용한 경우로 한정하였다.

\section{약물유도 수면내시경검사}

검사를 위해서 환자는 편안한 배게(pillow)를 동반한 침대 에 누워 앙와위 자세를 유지할 수 있도록 하였으며, 혈중 산 소포화도 $\left(\mathrm{SaO}_{2}\right)$ 와 심전도를 동시에 감시할 수 있는 모니터를 설치하였다. 이후 미다졸람(midazolam) $2 \mathrm{mg}$ 을 환자에게 정 주하여 가수면 상태를 유도하였으며, 가수면의 도달 여부는 bispectral index score(BIS) 모니터 시스템을 이용하여 평가 하였다. 본 연구에서는 BIS 수치를 50 65 사이로 유지 하였다. 환자가 가수면 상태에 도달하지 않을 경우에는 미다졸람을 $1 \mathrm{mg}$ 씩 추가로 천천히 투여하면서, 과수면(over-sedation) 상 태로 빠져들지 않도록 하였다. 환자가 가수면 상태에 도달한 후에는 코골이와 무호흡을 관찰할 수 있으며, 한 번 이상의 무호흡이 관찰된 이후 굴곡형 내시경을 이용하여 비강부터 하인두까지 수면 중 폐쇄되는 해부학적 위치를 관찰하였다. 모든 환자의 약물유도 수면내시경 검사의 프로토콜은 동일하 게 시행되었으며, 약물유도 수면내시경 검사 시간은 평균 29.8土 5.9(20 44)분이었다. 약물유도 수면내시경 결과는 2011년 Kezirian 등'이 제안한 “VOTE 분류법”을 바탕으로 폐쇄 부위 
(obstructive level)와 폐쇄 형태(obstructive configuration) 를 평가하였으며, 폐쇄 정도(obstructive degree)는 직경이 50\% 이상 좁아지는 경우 의미 있는 폐쇄가 있다고 정의하였다. 약 물유도 수면내시경 결과 해석은 녹화된 동영상을 보면서 두 명 이상의 이비인후과 의사에 의해서 독립적으로 시행되었고, 해석이 다른 경우 제 3 의 이비인후과 의사가 동영상을 보고 평가를 진행한 후에 3 명의 이비인후과 의사가 상의하여 결과 를 도출하였다. 전반적인 약물유도 수면내시경 검사 소견은 Table 1에 간략히 요약하였다.

\section{치료 방침}

본 연구는 약물유도 수면내시경검사가 도입되기 이전인 2009년 1월부터 2013년 2월과 약물유도 수면내시경검사가 도입된 이후인 2013년 3월부터 2016년 12월까지의 두 그룹을 나누어 비교 분석하였다. 그러므로 2009년 1월부터 2013년 2 월까지의 환자들은 의료진이 신체검진 소견과 수면 검사 결 과를 바탕으로 치료 방법을 제시한 그룹이고, 2013년 3월부 터 2016년 12월까지의 기간은 의료진이 신체검진 소견과 수 면 검사 결과뿐만 아니라 추가로 약물유도 수면내시경검사 결과를 바탕으로 환자에게 치료 방법을 제시한 그룹이다. 저 자들은 약물유도 수면내시경 검사를 시행하기 이전에는 중 증(severe) 폐쇄성 수면무호흡증 환자들은 우선적으로 양압 기 치료를 권유하였고, 경증 및 중등증(mild to moderat)의 폐쇄성 수면무호흡증 환자들은 신체검진 소견에 따라 의료 진이 판단하여 치료 방침을 결정하였다. 그러나 약물유도 수
면내시경검사를 시행한 이후에는 경증 및 중등증의 수면무 호흡증 환자들 중 심한 상기도 폐쇄가 다단계(multi-level)에 서 관찰되는 경우 양압기 처방을 권유하였고, 설근부에서 두 드러진 상기도 폐쇄가 관찰되면서 하악후퇴증(retrognathia) 이 동반된 경우에는 구강 내 장치 치료를 권유하였다.

\section{결 과}

2009년 1월부터 2013년 2월까지 기간 동안 수면 검사를 시 행 받은 환자 중 제외 기준을 고려하여 총 138 명의 환자가 본 연구에 포함되었고 평균 나이는 45.4 \pm 14.1 세, 성별은 남성이 98명(71.0\%), AHI는 22.3 \pm 7.6 이었다. 2013년 3월부터 2016년 12 월까지 수면 검사와 약물유도 수면내시경검사를 동시에 시 행 받은 환자 중 총 207명의 환자가 본 연구에 포함되었고 이 들의 평균 나이는 $44.4 \pm 16.1$ 세, 성별은 남성이 152 명(73.4\%), $\mathrm{AHI}$ 는 $20.7 \pm 9.2$ 이었다. 두 군간의 나이, 성별, $\mathrm{AHI}$ 수치간의 통계학적인 차이는 관찰되지 않았다.

약물유도 수면내시경검사의 사용이 의료진의 치료 방법 결 정에 미치는 영향을 살펴본 결과는 Table 2에 기술하였다. 약 물유도 수면내시경검사를 사용하기 전에는 수술적 치료가 $69.9 \%$ 로 의료진에 의해 주로 권유 되는 치료 방법이었으며 그 다음으로 구강 내 장치(14.5\%), 양압기(13.0\%) 등 비수술적 치료 방법이 해당되었고, 수술 및 구강 내 장치를 동시에 권 유하는 경우는 $2.9 \%$ 에 불과 하였다. 그러나 약물유도 수면내 시경검사가 상기도 폐쇄 부위 평가를 위하여 사용된 후에는

Table 1. Findings of drug-induced sedation endoscopy according to the VOTE classificatio

\begin{tabular}{lccr}
\hline \multirow{2}{*}{ Structure } & & Degree of obstruction & Complete obstruction \\
\cline { 2 - 4 } & No obstruction & Partial obstruction & $57(27.5)$ \\
\hline Velum (\%) & $41(19.8)$ & $109(52.7)$ & $42(20.3)$ \\
Oropharynx* (\%) & $40(19.3)$ & $125(60.4)$ & $115(55.5)$ \\
Tongue base (\%) & $37(17.9)$ & $55(26.6)$ & $49(23.7)$ \\
Epiglottis (\%) & $43(20.8)$ & $115(55.5)$ & Circumferential \\
\hline \multicolumn{1}{c}{ Structure } & & Configuration of obstruction & 37 \\
\hline Velum (\%) & Antero-posterior & Lateral & 50 \\
Epiglottis (\%) & 79 & 39 &
\end{tabular}

*obstruction of the oropharyngeal lateral wall or tonsils

Table 2. Change of treatment policy according to the DISE

\begin{tabular}{lcc}
\hline \multicolumn{1}{c}{ Type of treatment } & Physical examination only $(\mathrm{n}=138)$ & Physical examination \& DISE $(\mathrm{n}=207)$ \\
\hline Sleep surgery (\%) & $96(69.6)$ & $33(15.9)$ \\
Positive airway pressure* (\%) & $18(13.0)$ & $75(36.2)$ \\
Oral appliance (\%) & $20(14.5)$ & $55(26.6)$ \\
Sleep surgery \& oral appliance (\%) & $4(2.9)$ & $44(21.3)$ \\
\hline
\end{tabular}

*patients who had both positive airway pressure and nasal surgery also included. DISE: drug-induced sedation endoscopy 
양압기(36.2\%), 구강 내 장치(26.6\%) 등 비수술적 치료방법 이 의료진에 의해 주로 권유 되는 치료 방법으로 나타났으 며, 수술을 권유하는 경우, 수술만 권유하는 경우(15.9\%) 보다 수술 및 구강 내 장치를 동시에 권유하는 경우(21.3\%)가 높게 나타났다.

약물유도 수면내시경검사의 사용이 의료진의 치료 방법 결 정에 미치는 영향을 중증도에 따라 분석한 결과는 Table 3에 기술하였다. 경증 및 중등증의 폐쇄성 수면무호흡증에서는 약물유도 수면내시경을 사용 이전에는 양압기 처방이 없었다 가 약물유도 수면내시경을 사용한 이후 양압기 처방이 의료진 의 주된 치료방법 중 하나가 되는 현상을 관찰 할 수 있었으 며, 전반적으로 비술적 치료 방법으로 치료 계획이 결정되는 사례가 증가되는 양상이었다. 게다가 중증 폐쇄성 수면무호흡 증 환자에서는 약물유도 수면내시경을 사용 이후에는 치료 목 적으로 수술만 시행하는 경우가 $2.9 \%$ 로 감소되고, 대신에 양 압기(41.4\%)와 수술 및 구강 내 장치를 동시에 권유하는(48.6\%) 치료 방침이 증가하는 것으로 나타났다.

다음으로, 의료진이 결정하는 치료 방침에 대한 환자들의 순응도의 변화를 살펴보았다(Table 4). 약물유도 수면내시경 도입 이전에는 수술적 치료 방침만 환자들의 순응도가 $78.1 \%$ 로 높았고, 양압기와 구강 내 장치의 경우 환자들의 순응도 가 $30 \%$ 미만이었다. 그러나 약물유도 수면내시경 도입 이후 에는 환자들의 순응도가 각각의 치료방침에서 모두 $75 \%$ 이상 (수술 $87.9 \%$, 양압기 $76.0 \%$, 구강 내 장치 87.3\%)으로 분석되 었다. 이는 의료진이 어떠한 치료방침을 권유해도 환자들이 치료 방침에 대하여 잘 받아들이는 것으로 해석할 수 있다.

\section{고 찰}

수면상태에서 폐쇄성 수면무호흡증 환자의 상기도 폐쇄 부위를 직접적으로 평가하는 약물유도 수면내시경은 1991년 Croft와 Pringle ${ }^{10)}$ 에 의해 처음으로 소개되었다. 이는 문자 그대로 약물로 수면을 유도한 뒤 상기도의 역동적인 폐쇄 부 위 변화를 관찰하는 것으로써, 기존의 방법으로 관찰이 어 려웠던 후두개와 같은 하인두와 후두 부위 폐쇄를 진단하는 데 장점을 가지고 있으며, ${ }^{6}$ 확인된 폐쇄 부위에 따라 적절한 수술적 치료를 선택할 수 있어 불필요한 수술을 줄일 수 있는 장점을 지닌다. 연구 결과에 따르면 Mueller maneuver와 같 은 각성 시 시행하는 상기도 폐쇄 부위 검사에서 관찰되지 않 았던 후두개 폐쇄 부위가 폐쇄성 수면무호흡증 환자의 $22.7 \%$ 에서 약물유도 수면내시경 검사에서는 관찰되었다. ${ }^{11)}$ 또한 약 물유도 수면내시경 검사는 측와위 수면 자세 방법을 통해서 후두 및 설근부 폐쇄가 미치는 영향을 배제한 채 연구개 부 위 폐쇄가 폐쇄성 수면무호흡증 환자에서 어떻게 나타나는지 관찰할 수 있는 장점을 지닌다. ${ }^{12)}$ 그리고 이를 통해 의료진은 환자의 연구개 부위 폐쇄가 전후 방향으로 생기는지 외측 직 경이 좁아지는 외측 방향으로 폐쇄가 생기는지 독립적으로 평가할 수 있어 수술적 치료 방법의 선택에 도움을 받을 수 있다. 또한 검사 도중 턱을 앞으로 전진시켜 구강 내 장치를 착용한 것과 비슷한 동작을 만들어주고 상기도 폐쇄 부위가 완화되는지 여부를 관찰하는 것으로 구강 내 장치 이후의 치 료 성공 여부를 미리 예측하는데 도움을 줄 수도 있다. ${ }^{13)}$

폐쇄성 수면무호흡증 환자에서 약물유도 수면내시경을 이

Table 3. Change of treatment policy according to the DISE regarding severity of obstructive sleep apnea

\begin{tabular}{lcc}
\hline \multicolumn{1}{c}{ Mild to moderate obstructive sleep apnea } & Physical examination only $(\mathrm{n}=80)$ & Physical examination \& DISE $(\mathrm{n}=137)$ \\
\hline Surgery (\%) & $60(75.0)$ & $31(22.6)$ \\
Positive airway pressure* (\%) & $0(0)$ & $46(33.6)$ \\
Oral appliance (\%) & $20(25.0)$ & $50(36.5)$ \\
Surgery \& oral appliance (\%) & $0(0)$ & $10(7.3)$ \\
\hline \multicolumn{1}{c}{ Severe obstructive sleep apnea } & Physical examination only $(\mathrm{n}=58)$ & Physical examination \& DISE (n=70) \\
\hline Surgery (\%) & $36(62.1)$ & $2(2.9)$ \\
Positive airway pressure* (\%) & $18(31.0)$ & $5(7.1)$ \\
Oral appliance (\%) & $0(0)$ & $34(48.6)$ \\
Surgery \& oral appliance (\%) & $4(6.9)$ &
\end{tabular}

*patients who had both positive airway pressure and nasal surgery also included. DISE: drug-induced sedation endoscopy

Table 4. Change of patient's compliance to the treatment modalities after using DISE

\begin{tabular}{lcc}
\hline \multicolumn{1}{c}{ Compliance rate } & Physical examination only $(\mathrm{n}=138)$ & Physical examination \& DISE $(\mathrm{n}=207)$ \\
\hline Surgery (\%) & $75 / 96(78.1)$ & $29 / 33(87.9)$ \\
Positive airway pressure* (\%) & $3 / 18(16.7)$ & $57 / 75(76.0)$ \\
Oral appliance (\%) & $5 / 20(25.0)$ & $48 / 55(87.3)$ \\
Surgery \& oral appliance (\%) & $2 / 4(50.0)$ & $40 / 44(91.0)$ \\
\hline
\end{tabular}

*patients who had both positive airway pressure and nasal surgery also included. DISE: drug-induced sedation endoscopy 
용에 따른 치료 방법의 변화를 살펴본 기존 연구를 살펴보 면, 수면검사 결과와 신체검진 소견만으로 수술적 치료방법 을 결정한 후에 약물유도 수면내시경 검사를 추가로 시행하 여 수술적 치료방법의 종류가 변화되었는지 살펴본 연구에서 $78.4 \%$ 의 환자에서 수술적 치료방법의 종류가 달라진 것을 관찰하였다. ${ }^{8)}$ 또 다른 연구에서도 약물유도 수면내시경 후 $62 \%$ 에서 수술적 치료 계획이 변화되었다고 보고하였다. ${ }^{14)}$ 이 는 수술적 치료가 대상이 되는 폐쇄성 수면무호흡증 환자를 약물유도 수면내시경을 이용하여 보다 정교하게 치료 계획을 평가할 수 있음을 보여주는 연구이다. 본 연구는 선행 연구들 처럼 환자 각각에서 약물유도 수면내시경 검사 전후로 수술 적 치료의 종류의 결정이 어떻게 변화되었는지 살펴보는 연구 가 아니라 약물유도 수면내시경 검사가 도입되기 전과 후로 의 료진의 치료 방침(수술적 vs. 비수술적)이 어떻게 변화되었는 지 살펴보는 연구이다. 그러므로 서로 다른 환자 집단을 비교 하였기에 결과해석에 분명한 한계점을 지닌다. 그러나 나이, 성별, $\mathrm{AHI}$ 수치 등에서 두 그룹간의 통계학적인 차이가 없으 며, 기존 연구와는 달리 수술적 치료의 종류가 아니라 전반적 으로 의료진의 의사결정이 어떻게(수술적 Vs. 비수술적) 변화 되었는지 경향성을 살펴볼 수 있는 장점을 지니고 있다. 본 연 구에서는 약물유도 수면내시경 검사의 도입이 의료진의 치료 방침이 중증도와 무관하게 비수술적 치료에 대한 선호도가 증가되었음을 관찰할 수 있었다. 게다가, 양압기 혹은 구강 내 장치와 같은 비수술적 치료 방법에 대한 환자들의 순응도가 약물유도 수면내시경 검사 시행 이후에 두드러지게 증가하였 는데, 이는 환자들이 약물유도 수면내시경 검사 시 촬영된 동 영상을 통해 본인의 폐쇄 부위를 직접 영상으로 시청하는 과 정이 의사-환자 관계(doctor-patients relationship)에 긍정적 인 영향을 주었을 가능성이 있을 것으로 판단된다.

그러나 약물유도 수면 시 나타나는 상기도 변화가 정상 수 면을 얼마나 정확히 대변하는지에 대해서는 아직 이견이 있 다. 왜냐하면 약물유도 수면은 상기도 근육의 과도한 이완을 가져올 수 있어 위양성 소견을 보일 수 있으며, 약물유도 수면 에서는 일반적으로 3단계 non-rapid eye movement 수면과 rapid eye movement 수면이 출현하지 않아 실제로 존재하는 상기도 폐쇄 부위가 관찰되지 않을 수 있는 가능성이 있기 때문이다. ${ }^{15,16)}$ 최근에는 약물유도 수면내시경 검사에서 관찰 되는 multi-level 폐쇄 부위를 모두 수술적 치료를 하는 것 이 multi-level 폐쇄 부위가 관찰되더라도 인두 부위만 수술 하는 것에 비해서 보다 나은 무호흡-저호흡 지수 개선 효과 를 보이지 않는다고 기술한 연구결과도 있다. ${ }^{17)}$ 안타깝게도, 본 연구에서는 치료 후에 시행한 무호흡-저호흡 지수 측정결 과가 없어 약물유도 수면내시경 검사가 치료 성공률에 어떠
한 영향을 미쳤는지는 판단할 수 없다. 그러므로 앞으로 약 물유도 수면내시경 검사를 사용한 경우와 사용하지 않은 경 우 치료 성공률에 대한 수면 검사 비교 연구가 후속연구로 필요하다고 저자들은 생각한다.

\section{REFERENCES}

1) Epstein LJ, Kristo D, Strollo PJ Jr, Friedman N, Malhotra A, Patil $\mathrm{SP}$, et al. Clinical guideline for the evaluation, management and long-term care of obstructive sleep apnea in adults. J Clin Sleep Med 2009;5(3):263-76

2) Kapur VK, Auckley DH, Chowdhuri S, Kuhlmann DC, Mehra R, Ramar K, et al. Clinical Practice Guideline for diagnostic testing for adult obstructive sleep apnea: an American Academy of sleep medicine clinical practice guideline. J Clin Sleep Med 2017;13(3):479-504

3) Ramar K, Dort LC, Katz SG, Lettieri CJ, Harrod CG, Thomas SM, et al. Clinical Practice Guideline for the treatment of obstructive sleep apnea and snoring with oral appliance therapy: an update for 2015 . J Clin Sleep Med 2015;11(7):773-827.

4) Kushida CA, Chediak A, Berry RB, Brown LK, Gozal D, Iber C, et al. Clinical guidelines for the manual titration of positive airway pressure in patients with obstructive sleep apnea. J Clin Sleep Med 2008; 4(2):157-71.

5) Ravesloot MJL, de Vries N. One hundred consecutive patients undergoing drug-induced sleep endoscopy: results and evaluation. Laryngoscope 2011;121(12):2710-6.

6) Kezirian EJ. Nonresponders to pharyngeal surgery for obstructive sleep apnea: insights from drug-induced sleep endoscopy. Laryngoscope 2011;121(6):1320-6.

7) Vanderveken OM. Drug-induced sleep endoscopy (DISE) for nonCPAP treatment selection in patients with sleep-disordered breathing. Sleep Breath 2013;17(1):13-4.

8) Eichler C, Sommer JU, Stuck BA, Hörmann K, Maurer JT. Does drug-induced sleep endoscopy change the treatment concept of patients with snoring and obstructive sleep apnea? Sleep Breath 2013;17(1):63-8.

9) Kezirian EJ, Hohenhorst W, de Vries N. Drug-induced sleep endoscopy: the VOTE classification. Eur Arch Otorhinolaryngol 2011;268(8): $1233-6$.

10) Croft CB, Pringle M. Sleep nasendoscopy: a technique of assessment in snoring and obstructive sleep apnoea. Clin Otolaryngol Allied Sci 1991;16(5):504-9.

11) Cavaliere M, Russo F, Iemma M. Awake versus drug-induced sleep endoscopy: evaluation of airway obstruction in obstructive sleep apnea/hypopnoea syndrome. Laryngoscope 2013;123(9):2315-8.

12) Lee CH, Kim DK, Kim SY, Rhee CS, Won TB. Changes in site of obstruction in obstructive sleep apnea patients according to sleep position: a DISE study. Laryngoscope 2015;125(1):248-54.

13) Johal A, Battagel JM, Kotecha BT. Sleep nasendoscopy: a diagnostic tool for predicting treatment success with mandibular advancement splints in obstructive sleep apnoea. Eur J Orthod 2005;27(6):607-14.

14) Gillespie MB, Reddy RP, White DR, Discolo CM, Overdyk FJ, Nguyen SA. A trial of drug-induced sleep endoscopy in the surgical management of sleep-disordered breathing. Laryngoscope 2013;123(1):277-82.

15) Blumen MB, Latournerie V, Bequignon E, Guillere L, Chabolle F. Are the obstruction sites visualized on drug-induced sleep endoscopy reliable? Sleep Breath 2015;19(3):1021-6.

16) Stuck BA, Maurer JT. Airway evaluation in obstructive sleep apnea. Sleep Med Rev 2008;12(6):411-36.

17) Hsu YS, Jacobowitz O. Does sleep endoscopy staging pattern correlate with outcome of advanced palatopharyngoplasty for moderate to severe obstructive sleep apnea? J Clin Sleep Med 2017;13(10):1137-44. 